REVISTA DE LA UNIVERSIDAD DEL AZUAY

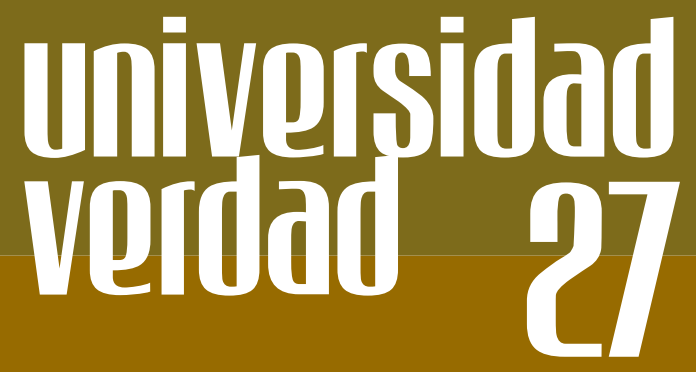

UNIVERSIDAD

DEL AZUAY

\title{
RECUPERANDO LA TRADICIÓN
}

Mario Jaramillo Paredes

Rector de la Universidad del Azuay 
Merecedora de reseñas en importantes publicaciones especializadas y causa de fértiles debates, la obra Educación Superior y Futuro de España, de Víctor Pérez Díaz, Profesor de la Universidad Complutense, se inicia con una exposición sobre la educación superior y sus tendencias actuales. Describe la experiencia norteamericana y analiza el estado de la universidad española a partir de sus ingredientes esenciales: los estudiantes, los profesores, el gasto institucional, la evaluación de la educación, la investigación científica y su capacidad para crear cultura. Algunas de las aseverciones tajantes pero sustentadas en datos objetivos nos dicen -en esta obra- que la Universidad, ni está muerta, ni goza de buena salud. Es quizá, un enfermo grave, pero recuperable. Señala que, probablemente, los estudiantes entran en un estado de semibarbarie en la Universidad y, salen, en un estado semejante. Los estudiantes tendrían -en estas circunstancias- capacidades comunicativas fragmentarias por la supremacía de una educación profesionalizante que no permite una visión integradora y amplia de lo que es el mundo actual. El discurso prevaleciente-dice- está centrado en la universidad pública y en la formación especializada, a su vez imitada de la experiencia norteamericana que, sin ser recomendable de modo absoluto ni exportable sin reservas, ha dado lugar a las mejores universidades de nuestro tiempo.

El autor de este análisis considera que una de las causas fundamentales de los males de la universidad española radica en la tendencia profesionalista y superespecializada que le ha dado cortedad de horizontes, pequeñez de aspiraciones y ausencia tanto de ambiciones como de perspectivas. Ese profesionalismo reduccionista ha vuelto a la universidad pragmática y utilitarista, rígida y propensa cada vez más a car en estereotipos o en velidades pasajeras. Concluye el autor que en estas circunstancias lo más avanzado podría consistir en la recuperación de la tradición medieval 
perdida cuando la universidad no era tanto preparación para el ejercicio profesional, sino una comunidad de estudiantes y profesores y una forma de vida consagrada a la búsqueda de la verdad para entender y forjar un mundo mejor.

Lo que en estos días se debate en las universidades españolas no tiene diferencias significativas con lo que es también motivo de amplias discusiones y análisis en otras universidades incluidas las norteamericanas. Es también lo que hoy -entre otros temas- nos congrega, es decir la necesidad imperiosa de volver a una educación integral que forme al estudiante con una visión amplia del mundo y con la perspectiva suficiente para intervenir activa y positivamente en él. Digo volver, porque es indiscutible que al hablar de formación integral no estamos inventando nada nuevo, sino volviendo -en el mejor sentido del término- a los orígenes de la universidad, es decir a a comunidad de seres humanos en búsqueda de la verdad. De una búsqueda que a veces se solaza con acercarse a la verdad y otras, adicionalmente, para con esa verdad transformar al mundo. $Y$, en esas dos posiciones, por supuesto tampoco nada hay de nuevo en la tradición moderna en donde las universidades son o somos centros en los cuales se privilegia la transmisión de conocimientos, la creación de ciencia aislada de la realidad circundante o, se utilizan esos conocimientos para hacer del nuestro un mundo mejor. En muchos de los grandes y paradigmáticos centros universitarios norteamericanos,europeos y asiáticos de nuestros días, en efecto, se ha dejado ya de lado la formación superespecializada prevaleciente en la segunda mitad del siglo pasado, para privilegiar en su lugar una formación integral de sus estudiantes. El esquema es simple y efectivo: en las carreras de pregrado, prima la formación general y, en el posgrado se especializa en un campo del saber. En un mundo cambiante tan aceleradamente como es el actual y lo será cada vez más en el futuro, es clave formar seres humanos y no un robot que, mecánicamente, hace aquello para lo que está programado. En un mundo con más incertidumbres que certezas es esencial educar para la incertidumbre, es decir formar personas que sepan enfrentar y afrontar lo incierto y lo complejo. El esquema de cursos de pregrado de carácter no profesional que cubran distintas áreas del conocimiento, 
es hoy urgente necesidad. Un esquema que permita al estudiante tener perspectivas más amplias, de la cultura y la sociedad y que aporte valores a la vez que genere actitudes responsables y críticas hacia su futura profesión así como hacia la sociedad en la que vive. Esta formación se comparte -en perfecta armonía- con la formación en valores que hace del estudiante un ser humano, solidario, tolerante y responsable. Es decir como debería ser y no como lamentablemente es.

Ligada directamente con la formación integral se encuentra la formación multidisciplinaria. En tiempos de globalización y de acelerado desarrollo del conocimiento, cuando los problemas tienen carácter multicultural y transterritorial, las limitadas fronteras de cada parcela del saber deben necesariamente ampliarse para dar cabida a una visión integradora del mundo y sus circunstancias, como diría el maestro Ortega y Gasset. Hoy ningún campo del saber puede -solamente con sus propios métodos- agotar la complejidad de su objeto y de la enmarañada trama de relaciones que tiene con otros saberes y campos de la vida tanto social como individual. Hoy, más que antes, se hace necesario avanzar hacia metodologías y campos de acción compartidos. El problema de la deuda externa-por ejemplocon todo su peso e incidencia en millones de seres humanos no se agota, ni remotamente, en las fórmulas macroeconómicas, ni en las químicamente puras disquisiciones economicistas. La cultura, la política, la antropología, pero por sobre todo la dignidad humana, imponen soluciones integradoras que vayan más allá de las simplistas recetas como cumplir con las imposiciones de los organismos internacionales o, como aquella, de no pagar la deuda. Las dos pseudo soluciones son claros ejemplos de visiones reduccionistas del complejo problema y no enfoques en donde prime la confluencia de fértiles perspectivas multidisciplinarias. De igual manera y, entre mil ejemplos, el problema de la educación en sus distintos niveles no es solamente asunto de métodos pedagógicos, de recursos económicos o de estructura organizativa. Es un problema de variados componentes que tienen que ver con las ciencias naturales y con las ciencias sociales y que como tal tiene que afrontarse desde una visión multidisciplinaria. Hoy y para nadie aquí es desconocido, la 
comunidad científica cada vez más ve la necesidad de revisar las fronteras epistemológicas para ampliarlas y hasta para borrarlas. El mundo -hoy más que nunca- no puede ser entendido como un conjunto de fragmentos sino como una unidad interrelacionada en donde, como se ha repetido tantas veces, el aleteo de una mariposa sobre el agua del mar puede causar un maremoto en la antípoda. Enunciado el problema de la multidisciplinariedad y la formación integral en los términos anteriores y en las soluciones integradoras, es tema aparentemente simple. Sin embargo, en la práctica, es tarea compleja por el peso de una tradición marcadamente profesionalizante; por la natural resistencia al cambio de muchos docentes que privilegian su campo de saber en desmedro de los otros campos y por la inmediatista ambición de muchos estudiantes que buscan pragmáticamente las herramientas de su profesión para lanzarse al mundo laboral, sin interesarse en conocer el verdadero mundo complejo e interrrelacionado en el que deberán vivir.

El Informe de la Comisión Gulbenkian para la Reestructuración de las Ciencias Sociales, informe que fuera coordinado por Immanuel Wallerstein, es posiblemente una de las más lúcidas reflexiones que se han hecho últimamente sobre este tema. Señala, entre otros puntos, que hemos llegado al fin de una racionalidad que no da más en sistemas estancos. Que es por ello necesario poner énfasis en lo complejo, en lo inestable es decir avanzar hacia la interdisciplinariedad. Ello no supone abandonar lo nuclear es decir la investigación en detalle sobre temas específicos y especializados, pero sí ir hacia sistemas integrados en que las partes se expliquen a partir del todo. Los principales problemas que enfrenta una sociedad compleja -como es la actual- no se pueden resolver -sostiene- descomponiéndola en pequeñas partes que parecen fáciles de manejar, sino abordando esos problemas y a la naturaleza, en toda su complejidad y sus interrelaciones.

Aun cuando pueda parecer una blasfemia se podría decir que hay un escaso desarrollo de la ciencia a partir de 1940. Nuestros padres y abuelos vieron más avances cualitativos que nosotros. Entre 1880 y 1940 surgió: la electricidad, radio, teléfono, motor, 
automóvil, avión y antibióticos. Luego sólo la energía nuclear cuyas aplicaciones prácticas son todavía muy limitadas en la vida diaria de la mayoría de la humanidad. Los viajes al espacio, la informática, la genética -igualmente-tienen influencia, más restringida a comunidades pequeñas, que a los individuos en su vida diaria. Quizá fruto también de la especialización es que el conocimiento actual es más cúmulo de información que planteamiento de soluciones o explicación total del mundo, es decir filosofía. Los pensadores desde el siglo XVIII hasta inicios del XX dieron sistemas y soluciones, cuestionados por supuesto, pero a la final sistemas. Los de hoy casi nada, salvo la precisión asombrosa en conocer detalles pero no visión de conjunto. Y ese esquema -posiblemente- está propiciado por la universidad superespecializada y profesionalizante, empecinada y alucinada por satisfacer las necesidades del mercado y el capital, antes que por servir al ser humano de carne y hueso que todavía sigue muriendo -cuando no de hambre- de enfermedades que debieron desaparecer hace muchos años. O por armas temibles y leyes, muchas de ellas desarrolladas en universidades o por hombres que un día pasaron por una universidad.

Juan Jacobo Rousseau decía que todo ser humano tiene tres deberes fundamentales. El primero, procrear hijos para perpetuar la especie, el segundo, hacer de esos hijos seres capaces para vivir en sociedad $y$, finalmente formarlos como ciudadanos aptos para desenvolverse en la gran sociedad que es el Estado. Como ocurre con muchos teóricos no cumplió en la práctica con lo que predicaba y abandonó a sus hijos. Para compensar lo que había dicho y no había hecho escribió sus dos monumentales obras: El Emilio y El Contrado Social, en las cuales aconseja cómo formar seres sociables y buenos ciudadanos, respectivamente. Pero, más allá de otras tesis que allí sustenta, uno de sus puntos fundamentales en el contexto que hoy nos ocupa, es la formación integral del ser humano. Para ello $y$, además de otras recomendaciones, señala que el estudiante -Emilio- después de aprender en la teoría, debe tener contacto con otras realidades: viajar y tener lo que hoy llamaríamos una educación internacional, entendida -diríamos nosotros- no como un turismo superficial sino como el encuentro fértil y motivador con otras culturas 
para dar al estudiante esa visión integradora y cosmopolita del mundo en que vive, así como elementos de juicio para actuar. Los prejuicios que surgen de una visión limitada y egocéntrica del mundo pueden ser superados, conociendo mejor otros sistemas de valores, otras concepciones de la vida, es decir otras culturas, entendido este término en el más rico sentido antropológico, es decir como las respuestas que el ser humano da a las necesidades materiales y espirituales con que le incita el entorno en el que vive, en palabras de Arnold Toymbee.

Hoy la mayoría de las universidades y escuelas politécnicas nos empeñamos en mantener y dinamizar programas de relaciones internacionales que deben entenderse como un puente entre la universidad, sus profesores y sus estudiantes y el exterior. Convenios de intercambio para enviar estudiantes fuera y recibir a los que vienen desde otras latitudes, son formas idóneas de internacionalizar la educación, es decir de vencer los límites siempre estrechos de una sola cultura. Son una forma de hacer universal a un ser humano y yo diría, de dar a la universidad su primigenio y siempre válido concepto de universalidad. Integrar no solamente la docencia sino llegar a programas integrados y compartidos de investigación, debería ser una meta deseable. Solamente cuando se llega a ese estadio de compartir proyectos de investigación, intercambiando experiencias, sumando fortalezas y aptitudes, es cuando podemos hablar de una educación realmente internacional que, lamentablemente, en la mayoría de los casos se queda solamente en el primer escalón, como es el de intercambio de estudiantes y profesores.

Hoy un gran refuerzo a ese cada vez más necesario proceso de una educación internacional es el de la variedad de redes universitarias, nacionales, regionales e internacionales, concepto que supera al de las asociaciones de universidades, generalmente vinculadas y a su vez limitadas, más por intereses casi gremiales, que por el superior objetivo de un avance de la ciencia y la cultura. Entre las limitaciones economicistas y de defensa de intereses que priman en las asociaciones y las miras más amplias que apuntan a la generación de ciencia y cultura de las redes existe, efectivamente, una significativa 
diferencia. Hoy, quizá, los avances más importantes en la dirección de la educación universitaria internacional, además del intercambio de recursos humanos e información y de compartir proyectos de investigación, van hacia la posibilidad de homologar estudios y títulos y, obviamente, de su reconocimiento legal. Dinamizar bibliotecas y centros de documentación enlazados en redes informáticas con las modernas tecnologías, es por supuesto, parte importante de la internacionalización, la transmisión y generación de conocimientos. Para ello requisito fundamental es el de la calidad de la educación que se imparte entre esos centros asociados. Simplemente es imposible pensar en esos niveles de internacionalización si es que no se parte de poseer los mejores niveles posibles de calidad.

Como se señala en un importante documento de la UNESCO la evolución de la ciencia y la educación ha reforzado la validez del argumento según el cual, puesto que el conocimiento es universal, su obtención y difusión deben también serlo. La movilidad de estudiantes y profesores, en este contexto y según la misma fuente adquieren una importancia mayor y más aún a la luz de las tendencias de integración económica, política y social, como las de nuestros días. Las tecnologías nuevas de información contribuyen poderosamente en esta dirección de internacionalizar el saber y la educación. En la década pasada según cifras de la UNESCO el número de personas que reciben educación fuera de su país de origen aumentó al menos en un treinta por ciento y la mayoría de ellas provienen de los países en desarrollo. Es decidor -de acuerdo a la misma fuente- que la mayor parte de esa movilidad se dio fuera del marco de programas de intercambio institucional, es decir se hizo por cuenta propia de los estudiantes. Uno de los problemas serios, por supuesto, es el del alto porcentaje de estudiantes que se quedan en el exterior, es decir no regresan a contribuir con su preparación al desarrollo del país del cual provienen. La paradoja, en este sentido, se da en términos de estudiantes de países subdesarrollados, nutriendo con su capacidad a los países desarrollados en los cuales se prepararon y en los cuales se quedan. Es parte de un fenómeno -como todos conocemos- de amplio movimiento de migración causado por factores económicos, políticos y sociales que obligan a la gente a buscar mejor suerte en 
el exterior.

La internacionalización de la universidad supone, además de compartir recursos humanos, experiencias y proyectos, una necesidad inherente al espíritu universal de la universidad como es el de ampliar horizontes, liberarse de los prejuicios, tener una visión integral del mundo en su rica complejidad cultural para conociéndolo mejor, lograr el respeto hacia otras formas de pensar y actuar. En suma para crear una cultura de tolerancia que tanta falta hace en el mundo actual. Vistos desde esta perspectiva los tres temas sobre los que se me ha pedido que reflexione, no son tres, sino uno solo que es el de búsqueda de seres humanos con una visión cosmopolita que rebase los límites cada vez más estrechos de una superespecialización.

Finalmente y en lo que tiene que ver con los sistemas internacionales de medición de la calidad de la educación superior, éstos son relativos y se encuentran mediados por una serie de factores dentro de los cuales, quizá los más significativos, son los que tienen que ver con las necesidades que cada país y sociedad tiene; sus objetivos, limitaciones y por sobre todo con las distintas percepciones que existen -muchas de ellas antagónicas- sobre el papel que la universidad debe cumplir. La calidad de la educación -la excelencia- se mide sin lugar a dudas en la relación que existe entre los fines buscados y los logros alcanzados. Es en síntesis la adecuación entre el deber ser y el ser de la educación superior. Según los últimos informes validados intrernacionalmente, por ejemplo, Finlandia es el país en donde un mayor porcentaje de estudiantes de escuela y colegio tienen un más alto promedio de capacidades para lectura comprensiva, mientras que Corea y Japón son los que tienen mejor desempeño en matemáticas y ciencia. Canadá ocupa el lugar cinco en el mundo y Gran Bretaña el seis, mientras Estados Unidos está en dieciséis y Alemania en el veinte.

Brasil con el más alto puntaje en América Latina, ocupa el lugar trigésimo segundo. Sobre la educación superior, lamentablemente, no disponemos de este tipo de medidas pero puede adelantarse que, siendo la educación escolar y la media, las bases sobre las que se 
sustenta la universidad, los resultados anteriores son decidores. Existen países y redes de universidades en los cuales la calidad de la educación se mide en términos de proyectos de investigación pertinentes que han concluido con éxito y han significado un real avance para el conocimiento. Hay parámetros que miden la calidad por el número de líderes y dirigentes que han entregado a la sociedad y al Estado. Hay otros que pesan por el número de premios Nobel que han salido de sus aulas o que dictan clases en esa Institución. Hay países que privilegian el nivel de contribución que una universidad ha dado para la solución de problemas sociales de la comunidad como la salud o la educación elemental y, hay quienes miden su calidad por las posiciones que en los diferentes campos de la actividad pública o privada ocupan sus graduados. De los pocos parámetros casi mundialmente aceptados, no puede dejar de mencionarse la calidad de los docentes, en el pasado y en la actualidad y la autoridad moral e intelectual que ello proporciona. Igualmente, la calidad de los estudiantes, el número de estudiantes por docente, el nivel y número de postgrados -especialmente doctorados- el impacto de las publicaciones científicas y, finalmente, la infraestructura. La medición de la calidad lleva implícita a la competitividad que obliga a un esfuerzo cada vez mayor en la búsqueda de mejores resultados. Un exceso de competitividad, sin embargo, puede ser negativo, pues genera acciones desleales entre instituciones. En la base de un sistema de calidad está siempre la flexibilidad de planes, programas y proyectos, además de la autonomía, que permite tomar decisiones sin presiones ni limitaciones externas. Flexibilidad para responder con agilidad al cambiante entorno y para crear o suprimir carreras. El nivel de intercambio con otros países es igualmente una medida de la calidad de la educación así como su capacidad de usar apropiadamente los avances tecnológicos. Una institución que trabaja con calidad se propone metas altas que son un fuerte reto frente a las necesidades de la sociedad en la que sus graduados van a actuar. Los niveles de exigencia son altos, tanto para la carrera como para la graduación y superan el simple cúmulo de información para llegar a tesis que supongan un real aporte. La relación entre egresados y graduados así como entre profesores a tiempo completo, investigadores y alumnos son otros tantos puntos que se toman en 
cuenta y que, ciertamente, constan en el proyecto de un sistema de evaluación y acreditación que fuera desarrollado por el CONUEP. Hoy más que nunca es urgente consolidar un sistema de acreditación en las universidades y escuelas politécnicas del Ecuador. En un país en donde la educación no rinde cuentas es importante iniciar ese proceso midiendo con parámetros de uso generalizado en otras latitudes y con adecuaciones a nuestra realidad, la calidad que nuestras instituciones brindan. Hoy, en el Ecuador empieza ya a suceder lo que en otros países ocurre desde hace siglos: quien ofrece una plaza de trabajo a un graduado pregunta cada vez más dónde obtuvo su título. Y más allá de muchos riesgos que ello entraña, es bueno en cuanto conjuntamente con los concursos de conocimientos, nos dice qué es lo que la gente busca y espera de nosotros.

La responsabilidad de la Universidad, hoy al igual que en el pasado, es grande. $Y$, foros como éste, nos ayudan a compartir y buscar ese futuro mejor que todos esperamos a través de la educación. 